\title{
PIK3CA NM_006218.1:C.1258T>C
}

National Cancer Institute

\section{Source}

National Cancer Institute. PIK3CA NM 006218.1:C.1258T>C. NCI Thesaurus. Code C98490.

A nucleotide substitution at position 1258 of the coding sequence of the PIK3CA gene where thymine has been mutated to cytosine. 